\title{
Determinants of the Acceptance of Mobile Payment Systems by E-Merchants
}

\author{
Daniel Możdżyński, Poznan University of Economics and Business, Poland \\ Wojciech Cellary, Poznan University of Economics and Business, Poland \\ (iD) https://orcid.org/0000-0001-8578-4307
}

\begin{abstract}
To be effectively deployed, a mobile payment (m-payment) system must be provided by e-merchants and accepted by e-consumers. Although the problem of acceptance of m-payment systems by e-consumers has been widely researched, there are few studies about what actually motivates e-merchants to adopt and deploy these systems in their businesses in the first place. The goal of this research was to discover the behavioral intentions of e-merchants to adopt and deploy an m-payment system. The interviews approach was applied to $347 \mathrm{e}$-merchants randomly selected from among the whole population of 47,457 independent business units selling goods online in Poland. The PLS-SEM method was applied to determine the relationship between variables. Unexpectedly, perceived risk was not a significant factor influencing e-merchants' intention to adopt an m-payment system. The e-merchants' behavioral intention was significantly impacted by the expected usefulness, perceived ease of deployment and use, perceived cost and price, and hedonic motivation.
\end{abstract}

\section{KEYWORDS}

E-Merchants, Intention of Use, Mobile Payment System, Online Shops, Payment Adoption

\section{INTRODUCTION}

Worldwide e-commerce continues to develop quickly. In 2017, the e-commerce share of retail sales in China exceeded 20\%, while in Korea and the UK - 15\%, in the US - 10\%, and in Germany, France, Japan, and Brazil it was between 5\%-10\% (Meeker, 2018). In many countries, e-commerce growth is accelerating; e.g., in the USA, year/year 2016/2017 growth was $16 \%$, while a year before it was $14 \%$. Currently, a trend to initiate e-commerce transactions from smartphones instead of computers is observed. In 2017, the usage of mobile apps devoted to shopping increased 54\% year/year, while the average mobile app usage has grown only 6\% (Klotzbach, 2017). When shopping online with a mobile device, the best way to pay is provided by m-payment systems, i.e., any payment system that is installed on a mobile device such as a smartphone, tablet, smartwatch, or other wearable. In 2016, transactions conducted via such systems were estimated to total US $\$ 41.8$ billion globally, comprising $8.6 \%$ of all non-cash transactions (Bose \& Mellado, 2018).

For an m-payment system to be effectively deployed, two conditions must be met: (1) the system must be provided to consumers as a payment option by e-merchants, i.e., merchants selling on-line, and (2) the system must be accepted by e-consumers when completing their on-line transactions. The problem of acceptance of m-payment systems by e-consumers that has been widely investigated. In 
2015, Dahlberg et al. presented a critical literature review (Dahlberg et al., 2015) on this problem. Dahlberg et al. concluded that there is no need to conduct additional research on the acceptance of m-payment systems by e-consumers because we still do not know much about the acceptance of $\mathrm{m}$-payment systems by e-merchants. In addition, they noted that it is unclear what determines the decisions of e-merchants to deploy m-payment systems in their businesses. Dahlberg et al. strongly encouraged scientists to collect data from the real world, i.e., to collect data about real m-payment systems from real e-merchants.

Teo et al. (2005) interviewed randomly selected businesses to explore inhibitors and facilitators of $\mathrm{m}$ - payment adoption in Australia. They found that some businesses were reluctant to trial $\mathrm{m}$-payments before mass acceptance.

Mallat and Tuunainen (2008) conducted an exploratory study dominated by a qualitative methodology in Finland to organize determinants of merchants' adoption intention. They found lack of standardization and critical mass, as well as complexity of m-payment systems to be among the main adoption barriers.

Van Der Heijden (2002) interviewed 13 executives in Sweden and the Netherlands who were directly responsible for the deployment of mobile payment systems. They found that ease of use is important in establishing a merchant's acceptance of an m-payment system.

Lai and Chuah (2010) also attempted to explore merchant adoption, although they conducted their interviews with industry experts rather than with the merchants themselves.

Silenzi's doctoral research (Silenzi, 2012) involved interviews with managers from 15 international companies. He found that the key benefits of $\mathrm{m}$-payments for merchants is in facilitating purchases from unbanked users, increasing impulse purchases, and developing new business models.

Guo and Bouwman (2016) proposed a framework for the analyses of the m-payment ecosystem. Starting from a set of propositions, they conducted in-depth interviews to analyze the multifaceted nature of the Chinese m-payment market. They identified the connection between the adoption process and the business ecosystem configurations.

Mondego and Gide (2018) provided a comprehensive review of studies on consumers published between 2013 and 2017 in which trust was one of the main variables in their research models. The findings of this preliminary study suggest that trust does indeed impact the consumers intention to adopt the m-payment system. However, various authors in consumer intent research reports have suggested that trust is positively related to other factors such as perceived usefulness, ease of use, and perceived risk. Consequently, trust is known to be associated with the acceptance or adoption of the m-payment systems by consumers. Yang et al. (2015) suggests that "in the current stage of China's online payment systems evolution, consumers have built up trust first as an antecedent of their perceived risks". The significance of these factors is also consistent with the results of qualitative research conducted on e-merchants (Możdzyński, 2018).

Liébana-Cabanillas et al. (2016) revealed that merchants have an overarching affinity for financial institutions providing m-payment services and that lack of knowledge and lack of critical mass are the dominant barriers of merchants' adoption of m-payment systems. As a preliminary study, only basic statistical analysis has been conducted.

Liébana-Cabanillas et al. (2017) found that the lack of information on the new payment tools significantly hinders their adoption. As a preliminary study, this research only included a basic statistical analysis.

Ligon et al. (2019) found that low rates of adoption were due to demand-side factors or taxes. Specifically, they found direct evidence that demand-side factors such as a perceived lack of customers wanting to pay digitally and concerns that records of mobile payments might increase tax liability impacted merchant adoption of m-payment systems.

The literature review led to the conclusion that the authors of papers mentioned above do not distinguish e-merchants selling on-line from merchants selling in brick-and-mortar shops in the context of acceptance of mobile payments. On the other hand, the technology acceptance models 
used to explain e-consumers' likelihood of future use of an m-payment method do not include factors that explain the likelihood that an e-merchant will deploy an m-payment option for its customers. Therefore, it is necessary to develop a new model that specifically addresses the e-merchant's intention for deployment of an m-payment system. We refer to this intention as "Behavioral Intention", meaning the likelihood or the subjective probability that a person will engage in a given behavior (Armitage \& Conner, 2001).

We assume that off-line and on-line merchant's intentions of using an m-payment system differ significantly because of the wide range of technical environments that the m-payment system has to be integrated with. Also, the characteristics of a customer buying in a brick-and-mortar shop and paying with her mobile device to a physical terminal are different from a customer making both purchase and payment on-line. These different characteristics of customers may influence merchants' intentions. Therefore, this paper focuses only on e-merchants selling on-line. The overall goal of the research presented in this paper was to discover the behavioral intention of e-merchants to deploy an m-payment system in their business. Potentially, elements of a model describing the intention of e-merchants with respect to a topic like this could be identified on the basis of three different sources: empirical studies, theory, or economic practice (Webster \& Watson, 2002). In this case, it was necessary to conduct empirical studies, because, as stated above, a theory of e-merchant behavioral intention has not yet been developed and observations of practice related to e-merchant behavioral intentions have not been yet carried out (Możdżyński 2018). The aim of the empirical studies presented in this paper was to identify variables that best explain the expressed behavioral intention with respect to the adoption and deployment of an m-payment system (de Graaf et al.. 2017).

The research was conducted in three phases. First, a qualitative study was carried out according to the Schweitzer and van den Hende method (Schweitzer \& Van den Hende, 2016) to identify variables best explaining the studied phenomenon. Next, a model of acceptance of m-payment systems by e-merchants, called MTAUT (Merchant Theory of Acceptance and Use of Technology), was developed. The MTAUT model is composed of five constructs and five moderators. Five main hypotheses and 25 specific hypotheses were formulated to examine the significance of the impact of the variables on the behavioral intention of e-merchants. Finally, the hypotheses were tested using data collected from 347 e-merchants who were interviewed using the Pen \& Paper Personal Interview (PAPI) technique (Jones, 2018).

The 428 e-merchant participants were randomly selected from among the whole population of 47,457 independent business units selling goods on-line in Poland. Each e-merchant interviewed represented a different and independent business unit. Each interview involved personally meeting with a project assigned researcher and receiving a presentation of an original m-payment system called eXpay (Możdżyński, 2017) that potentially could be deployed in the e-merchant's business. The presentation of this system aroused interest of 375 e-merchants who agreed to spend time answering the MTAUT survey questions. Due to this orientation to eXpay system, the subsequent interview answers of e-merchants were expected to be more precise and more consistent than if they were simply related to an abstract and generally characterized m-payment system. The research was conducted in Poland. According to Bright and McKenzie-Minifie (2015), Poland is one of the countries with the highest share of "mobile shoppers".

The remainder of this paper is organized as follows. In Section 2, the current Models of Technology Acceptance are briefly presented. Section 3 presents the conceptual background of m-payment systems. In Section 4, exploratory qualitative research is described aiming at identification of constructs and moderators of the MTAUT model explaining the intention of e-merchants to deploy an m-payment system. Then, the MTAUT model is presented. In Section 5, hypotheses are formulated. In Section 6 , quantitative research is described aiming at hypotheses verification. Evaluation of collected data reliability and validity is presented. In Section 7 research results are presented including the statistical studies conducted to analyze the data collected. Section 8 is devoted to the discussion of the results obtained. Section 9 contains some recommendations for future research. 


\section{STATE OF THE ART IN MODELS OF TECHNOLOGY ACCEPTANCE}

Behavioral models that come from different research areas are used to study consumer behavior. Three approaches most often used in empirical studies, derived from the mainstream of research on attitudes and information systems are:

- Ajzen's Planned Behavior Theory (TPB),

- Davis's Technology Acceptance Model (TAM), and

- Venkatesh's et al. Unified Theory of Acceptance and Use of Technology (UTAUT).

A synthesis of the use of acceptance models is presented in (Lai 2009).

Ajzen's approach, called Planned Behavior Theory (TPB) (Ajzen, 1985), was developed from the Theory of Reasoned Action proposed by Fishbein and Ajzen (1975). The TPB theory was created for general purposes and only later adapted to the needs of internet research. It turned out that its predictive power is sufficient to explain the behavior of internet users.

The Technology Acceptance Model (TAM) was specifically tailored for modeling users' acceptance of information systems or technologies. TAM is currently one of the most important theories explaining the individual's involvement in the use of new technology. It is widely applied to explain the use of a wide range of information technologies in different social contexts. TAM was also used in research on the acceptance of e-commerce. As follows from (Koufaris, 2002), TAM explains consumer behavior in case of on-line shopping very well.

Davis, like Ajzen, assumed that acceptance of information technology is directly determined by the behavioral intention to use it. Intention is explained by the attitude towards the use of a given technological solution (attitude toward using), its perceived usefulness for the user, and the perceived ease of use.

Venkatesh et al. revised and combined the constructs of eight models, including TPB and TAM, which - as follows from their research - best explain the behavior associated with the use of information technology (Venkatesh et. al., 2003). In this way, the Unified Theory of Acceptance and Use of Technology (UTAUT) was created. It aims to explain the intention of using information technologies and behaviors resulting from this intention. According to Venkatesh et al., UTAUT permits us to estimate the probability of success in the use of new technology and helps to understand the factors conditioning its acceptance.

The key role in UTAUT is played by four constructs that have a direct impact on the intention to use, and - as a result - on behavior: (1) performance expectancy, (2) effort expectancy, (3) social influence, and (4) facilitating conditions understood as favorable circumstances. Moreover, it is assumed in UTAUT that there are four variables moderating effects of these constructs on the intention of using technology and behavior: (a) gender, (b) age, (c) experience, and (d) voluntary use.

Lai et al. (2009) used UTAUT in their research on mobile commerce. They extended UTAUT with a construct addressing user concerns about possible problems related to the use of mobile commerce. The results obtained proved that the model. when extended with the construct concerning a negative factor, explains not only the positive but also the negative user's intention regarding the use of mobile commerce.

Venkatesh et al. (2012) proposed and tested the UTAUT2 model, which incorporates new constructs that focus on new theoretical mechanisms in a consumer context (hedonic motivation, price value, and habit).

$\mathrm{Wu}$ and Wang (2005) adapted the extended version of TAM, integrated it with the theory of innovation diffusion (Rogers, 1995) and added constructs of perceived risk and perceived costs. Then, using the modified model, they identified the factors responsible for the consumer's acceptance of mobile commerce. The results obtained by them indicate that the direct predictor of the use of mobile 
commerce is the user's intention, which in turn is significantly influenced by perceived risk and costs as well as the compatibility and usability of this form of transaction.

\section{CONCEPTUAL BACKGROUND}

\section{Mobile Payments Models}

Several authors, such as Au and Kauffman (2008) and Kousaridas et al. (2008), agree on the idea that $\mathrm{m}$-payment involves buying goods or services by using a mobile device.

There are five primary models for m-payments ("The Mobile Money Revolution Part 1: NFC Mobile Payments" 2013):

a. Mobile wallets;

b. Card-based payments;

c. Carrier billing (Premium SMS or direct carrier billing);

d. Direct transfers between the payer and payee bank accounts in near real-time (bank-led model, intra/inter-bank transfers/payments that are both bank and mobile operator agnostic).

e. Contactless payments NFC (Near Field Communication).

In this paper, we focus on m-payment models (a-d). We excluded investigating the adoption of $\mathrm{m}$-payments by the NFC, because it is used only in physical Point-Of-Sales (POS).

\section{Mobile Payment Business and Technology Environment}

To conduct business on-line, e-merchants need facilitating conditions. In the UTAUT model (Venkatesh et. al. 2003), facilitating conditions are defined as the degree to which an individual - in this case an e-merchant - believes that an organizational and technical infrastructure exists to support the use of the system. The readiness of an e-merchant to receive m-payments depends on his/her ability to provide mobile consumers ( $\mathrm{m}$-consumers) with a friendly platform to present business offers.

The checkout process is a critical component of the e-commerce experience. It is not only about API integration with the payment operator. It is where a sale transaction is either committed or abandoned. Most merchants spend a lot of effort optimizing their desktop payment checkout process, but they do not pay enough attention to the specificity of the m-payment checkout process (Welch, 2017).

An e-merchant may either use a website or develop a native m-payment application. There are two ways to adapt an e-merchant's website to mobile devices (Hussain \& Mkpojiogu, 2015). First, to develop a separate mobile website. This approach shortens load times and improves navigation on mobile devices but increases the costs of maintenance. Second, to apply responsive web design that makes web pages adjust to the size of any device's screen, irrespective of the device type.

To deploy m-payments, an e-merchant may develop a native m-payment application and integrate it with his/her mobile shop (Charland \& Leroux, 2011). A native application permits an m-consumer to remain in the mobile shop during the whole purchasing process including payment. This approach reduces the probability of abandoning the purchase process when switching to the separate payment operator's website. It is well established that every extra step the customer must take between completing their current shopping basket and checkout is an opportunity for them to abandon their basket and the payment process (5 Keys to Help Avoid Cart Abandonment, 2016). In addition, a native m-payment application may be integrated with warehousing, accounting and reporting systems.

The needs and behaviors of mobile consumers are not the same as desktop consumers. Mobile consumers are often on-the-go, trying to accomplish a task, or even multiple tasks, between other activities. That means speed is essential. They are using fingers and thumbs, which have wider margins of error than a trackpad or mouse. It is more arduous to click through to a new field or page on mobile 
than it is on a keyboard. Mobile checkout needs to be designed with these specifics in mind. Below, we list desirable features and design elements.

- Optimized Fields. Fields on smartphones are small, so inserting text information using fingers and thumbs is more difficult than on a desktop's full-sized keyboard. To get an m-consumer though a checkout process as fast as possible, it is recommended to reduce the number of fields requiring text entry, to provide for inserting vocal information, and to provide auto-correction.

- Autofill. Using information stored by an m-consumer on his/her smartphone, an e-merchant may autofill it and thus reduce text information that must be inserted manually.

- Vertical Alignment. Unlike desktop e-consumers who prefer horizontal alignment of pages, $\mathrm{m}$-consumers prefer vertical alignment of consecutive pages they must visit during the checkout process. Therefore, the checkout interface of a mobile application should be designed in accordance with this preference to facilitate m-payment.

- Progress Indicator. A progress indicator helps users to forecast the time required to complete a transaction. It is particularly important to m-consumers who need to know, for example, if they are able to complete a transaction before the next bus stop where they leave the bus.

\section{METHODOLOGY}

In the first phase of the project, we conducted an exploratory qualitative research to identify the variables, i.e., constructs and moderators, of the research model MTAUT. In the second phase, we developed model MTAUT and we made hypotheses. Finally, in the third phase, we conducted a quantitative research to verify them. This procedure is described in more detail in the following sections.

\section{Qualitative Research}

Exploratory qualitative research was conducted in the first phase of this project according to the Schweitzer and van den Hende (2016) method using the Paper and Pencil Interviewing (PAPI) technique (Jones, 2018), ("Paper And Pencil Interviewing") . This technique employs a modified form of personal interviewing, where the pollster holds a printed questionnaire, reads the question to the respondent, and records the answer onto the questionnaire. PAPI requires well-trained pollsters, whose skilled approach and communication with the respondents forms the basis for their ability to collect meaningful information about their stands, beliefs, and opinions on a given research subject. It is thought that such personal contact by an interviewer with participants elicits richer and more detailed responses. Pen-and-paper surveys are also guaranteed to produce a permanent primary record as a by-product of data collection.

The purpose of this phase was to determine the factors that might most influence a merchant's intention to adopt and deploy an m-payment system.

The procedure followed for this first phase of the research was:

1. First, 78 representatives of local e-merchants were visited and provided with the description and demonstration of the eXpay m-payment system (Możdżyński, 2017).

2. Next, they declared perceived advantages and disadvantages of eXpay.

3. Next, e-merchants' responses were analyzed to assign similar elements to categories.

4. Finally, the number of collected mentions of elements of particular categories were ranked against each other. 


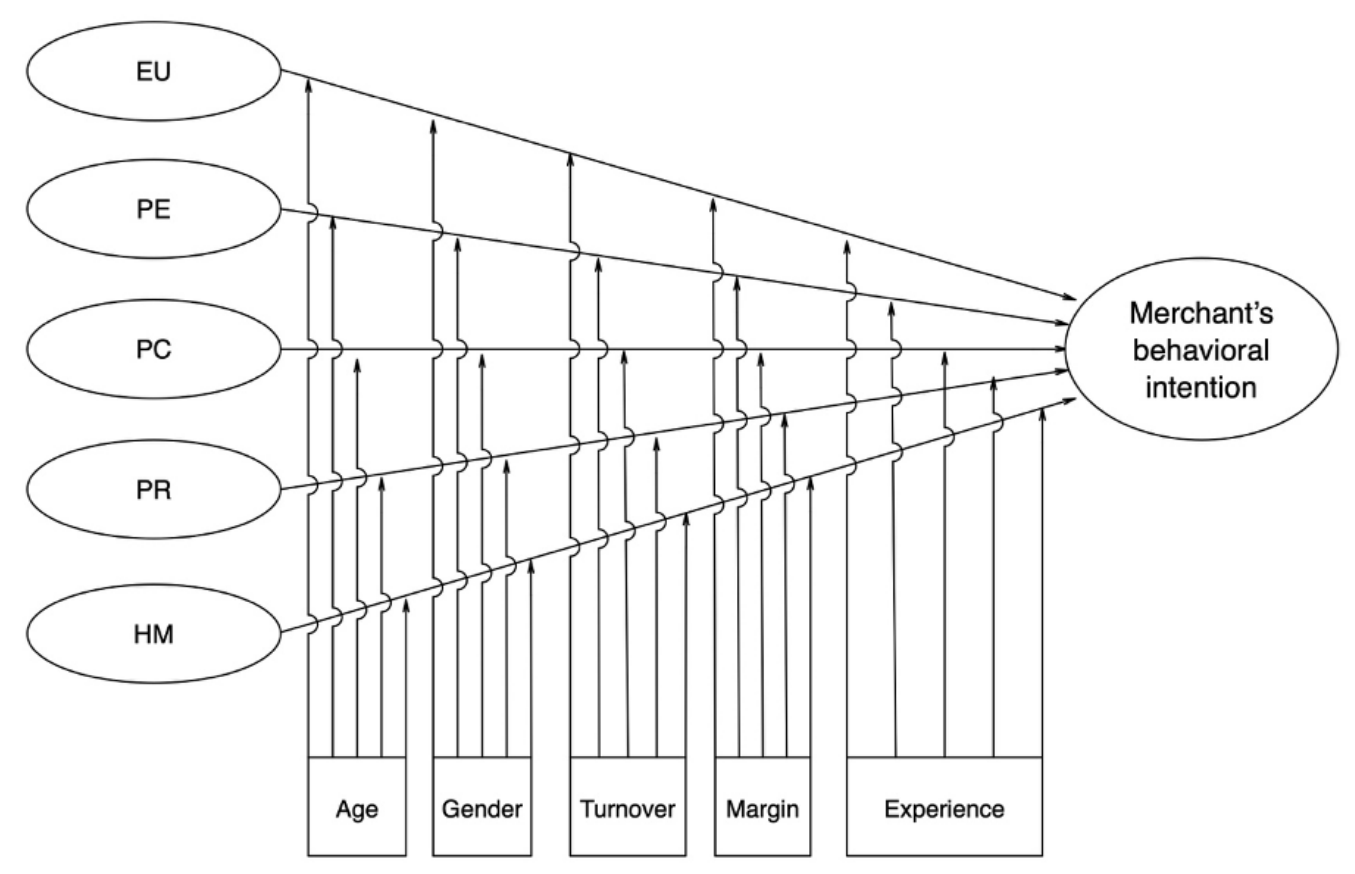

Categories whose elements were mentioned at least five times became MTAUT model variables. Appendix 1 presents those categories together with examples of mentions. Preliminary exploratory qualitative research is described in (Możdżyński, 2018).

\section{The MTAUT model}

The MTAUT model following from the exploratory qualitative research is depicted in Figure 1.

Arrows in this model indicate the necessity of verification of construct influence on merchant's behavioral intention to deploy and m-payment system, as well as moderating effect of moderators.

The following is an interpretation of the MTAUT constructs:

1. Expected usefulness (EU) influences an e-merchant's conviction that the use of an m-payment system will provide him/her with benefits.

2. Perceived Ease of deployment and use (PE) is defined as how easy an e-merchant assumes it will be to deploy, maintain, and use an m-payment system.

3. Perceived Cost (PC) of an m-payment system that the e-merchant expects to have to cover if he/ she purchases an m-payment system for his/her business.

4. Perceived risk (PR) includes an e-merchant's perception of the risk of cooperation with an m-payment system provider and trust based on provider reputation concerning transaction security.

5. Hedonistic motivation (HM) concerns joy and pleasure an e-merchant expects from using an m-payment system.

The following are MTAUT moderators:

1. Age of an e-merchant. 
2. Gender of an e-merchant.

3. Turnover of an e-merchant's company.

4. Margin of profit of an e-merchant company.

5. Experience in IT systems declared by an e-merchant or his/her deputy making business decisions.

\section{HYPOTHESES}

This section presents hypotheses aimed at examining the relationship between the variables in the MTAUT model,

1. Expected Usefulness (EU). The Expected Usefulness of an m-payment system reflects an e-merchant's expectation of the amount of benefits (e.g. achieving business goals and improved efficiency) that the e-merchant expects to accrue by using an m-payment system. As a result of exploratory qualitative research carried out on e-merchants, we found that the EU of an m-payment system may impact e-merchants' intention to adopt one. Expected Usefulness also appears in numerous studies examining consumer intention. However, EU has yet to be confirmed to be a significant determinant in the decision by an e-merchant to deploy an m-payment system (Dahlberg et al., 2015). Therefore, we propose the following hypothesis:

H1: Expected Usefulness (EU) has a positive relationship with the reported intention of e-merchants to deploy an m-payment system.

2. Perceived Ease (PE). The Perceived Ease of deployment and use (PE) is defined as how easy an e-merchant assumes it will be to deploy, maintain, and use an m-payment system. We propose the following hypothesis:

$\mathrm{H} 2$ : Perceived Ease of deployment and use (PE) has a positive relationship with the intention of e-merchants to use an m-payment system.

3. Perceived Cost (PC). The Perceived Cost of an m-payment system is the amount of money that an e-merchant expects to have to cover if he/she purchases an m-payment system for his/her business. Such costs may include:

- Sales commission;

- Cost of integration of the m-payment system with the e-shop;

- Adjustments of the administration panel of the m-payment system to the needs of e-commerce platform used by the e-merchant;

- Integration of the m-payment system with such merchant's systems as:

- warehouse management,

- finance and accounting,

- e-banking,

- ERP,

- business intelligence;

- Integrating the m-payment system with the native e-merchant's mobile application;

- Modernizing the hardware and software infrastructure;

- Training employees.

Therefore, we propose the following hypothesis:

H3: Perceived low cost has a positive relationship with the intention of e-merchants to deploy an m-payment system.

4. Perceived Risk (PR). The Perceived Risk of deployment of an m-payment system by an e-merchant focuses on his/her relationship with the m-payment system provider who serves as an intermediary between the e-merchant and a customer. The Perceived Risk concerns the responsibility of the provider for security standards and technical security solutions applied to 
the m-payment system. Some e-merchants consider mobile devices as less technically secure and more susceptible to cybercriminals. Some of the interviewed e-merchants indicated that after a cyberattack on a customer account or device, followed by intercepting customer login and password details, they are often blamed by harmed consumers for fulfilling cybercriminal orders that were "properly authorized and paid for". Other e-merchants mentioned the potential risk of financial loss due to the need to return funds to defrauded consumers for orders already completed by e-merchants.

Therefore, we propose the following hypothesis:

H4: Perceived increased Risk (PR) has a negative relationship with the intention of e-merchants to use an m-payment system.

5. Hedonic Motivation (HM). In this study, Hedonic Motivation concerns the joy and pleasure that a merchant expects from deploying an m-payment system. During the interviews, some e-merchants described the satisfaction of visually matching the graphic design of the m-payment system to the colors of their e-shop. Other e-merchants mentioned the satisfaction and pleasure resulting from the mere fact of adapting their shops to m-payment. Based on qualitative research, we assumed that hedonistic motivation can be an important factor for e-merchants. Therefore:

H5: Hedonic motivations are positively related with an e-merchant's intention to use an m-payment system.

6. Moderators. Moreover, based on the exploratory qualitative research on e-merchants, five subhypotheses, one for each of the moderators, were derived for each hypothesis in the following way:

Hx.1 The age of e-merchants significantly modifies Hx.

Hx.2 The gender of e-merchants significantly modifies Hx.

Hx.3: The turnover of e-merchants' companies significantly modifies Hx.

Hx.4: The margin of e-merchants' companies significantly modifies $\mathrm{Hx}$

Hx.5: E-merchant's IT experience significantly modifies Hx.

\section{DATA COLLECTION AND RELIABILITY}

In this section, we present the quantitative research aiming at data collection and tests carried out to check data reliability. Empirical data were again gathered using the Paper and Pencil Interviewing (PAPI) technique (PAPI) technique (Jones, 2018), (Paper And Pencil Interviewing).

On April 19, 2018, all 47,457 independent business units selling goods on-line in Poland were downloaded from the Polish National Business Registry. The number of randomly drawn entities in this study was 428. Participants of this study were randomly selected from this group using the Excel function RANDBETWEEN. As follows from (Hair et. al., 2017), the minimum size of the research sample for the data analysis using the PLS structural equations should be ten times the largest number of structural paths running to a given latent construct. This requirement is observed. Also, recommendations of Goodhue, Lewis, and Thompson (2006) on how to calculate the minimum sample size are observed.

The survey reported in this paper of this group of selected businesses was conducted between April 23, 2018, and December 3, 2018. A copy of the survey using questions composing the questionnaire measured on the 7-point Likert scale is presented in the Appendix 2. From the selected sample, 53 e-merchants refused to meet after becoming acquainted with the purpose of the research and the topic proposal. A total of 28 participants in the study did not complete the questionnaire. They interrupted the study because of other duties. Their incomplete responses were therefore disregarded, and the questionnaires were considered invalid and rejected in their entirety. The number of correctly completed interviews was 347.

The average age of interviewed e-merchants was $\bar{X}=34.14$ years, standard deviation of $\mathrm{SD}=6.96$ years (range $=19-52$ ). From among 347 interviewed e-merchants, 91 were women and 256 men. The turnover of sales declared per year was between the US $\$ 0-$ US $\$ 5,308,982$. The margin was 
between $0-54 \%$ of sales. From among interviewed e-merchants, 68 declared experience in IT, while 279 did not.

Before completing the survey, the participants were familiarized with the capabilities of the eXpay m-payment system (Możdżyński, 2017).

\section{Reliability and Validity}

Variables were checked for reliability and accuracy of the measurements - c.f. Tables: 1 and 2. The calculations were made in the WARP PLS 6.0 program (Kock, 2010). The aim of the analysis was to test linear relationships between constructs using reflective variables (Kock, 2010). The PTH2 algorithm included in the WARP PLS 6.0 package was used for the calculations. This algorithm takes into account the relationships between variables that build latent variables and controls the error of measuring latent variables based on composite reliability coefficients (Kock, 2017).

The most interesting results are italicized in Table 1 . The analysis showed that the collected data were convergent with the measurement model SRMR $=0.051$, SMAR=0.038 (Iacobucci, 2010), and these variables were characterized by high reliability of measurement $\alpha=0.94-\alpha=0.98$ / CR $=0,96$ - 0.98 / AVE $=0.87$ - 0.94. The statistics indicate that the measurement part of the structural model was well-fitted with the collected data, i.e., individual variables were accurately measured. The measurements were also free of collinearity, which indicates that each variable under study explained peculiar variability in explaining intention (Kock and Lynn, 2012), and Tenenhaus et. al. (2005).

The analysis of quality factors and data matching to the structural model showed a very strong convergence of $\mathrm{GoF}=0.57$ (Kock, 2017) and Tenenhaus et. al. (2005). Path coefficients were similar to the correlation coefficients, which indicates a lack of statistical suppression (Pearl, 2009). The Sympson paradox (Pearl, 2014) measure $=1$, as well as the factor NLBCDR $=1$ indicate the correct reproduction of the causality of the path diagram (Figure 2), (Kock \& Gaskins, 2016).

All variables explained about $35 \%$ of the variability of merchant's m-payment system adoption: $\mathrm{R} 2=0.35$.

According to Hair et. al. (2011), R2 values equal to or higher than 0.20 are considered high in disciplines such as consumer behavior and success driver studies

For the purpose of statistical significance assessment, alpha $=0.1$ was assumed.

The star symbols $(*)$ used in the table mean statistical significance codes: *** mean 0 and ** mean 0.001 .

The PLS-SEM method (Kock \& Mayfield, 2015) was applied to determine the causal relationship between constructs, moderators, and merchant's m-payment system adoption. The PLS-SEM method permits the researcher to determine the strength of the individual impact of individual variables on the intention. To analyze moderation, the method of Full Latent Growth Analysis (Koufaris, 2002) was applied.

\section{RESULTS}

The analysis of path coefficients showed that the increase in m-payment system adoption of merchants was significantly related to the increase in the level of variable PE: $\beta=0.29 ; p<0.001 ; \mathrm{PU}: \beta=0.19$; $\mathrm{p}<0.001 ; \mathrm{PC}: \beta=0.33 ; \mathrm{p}<0.001$, and HM: $\beta=0.08 ; \mathrm{p}=0.073$.

The causal relationship between latent variables and the magnitude of the explained variance is presented in Table 3, and Figure 2.

Table 4 shows how and how strongly constructs and moderators of MTAUT impact e-merchant's intention to deploy an m-payment system.

The analysis concludes with high confidence that an e-merchant's conviction that high expected usefulness of a system (EU) positively affect the intention to deploy the system. The impact of the PU construct is relatively strong as compared to the other constructs of MTAUT. 
Table 1. Data matching for the measurement and the path model

\begin{tabular}{|l|l|}
\hline Coeff & Value \\
\hline Average path coefficient & $0.19^{* * *}$ \\
\hline Average R-squared & $0.35^{* * *}$ \\
\hline Average adjusted R-squared & $0.34^{* *}$ \\
\hline Average block VIF & 42736 \\
\hline Average full collinearity VIF & 47119 \\
\hline Tenenhaus GoF & 0.57 \\
\hline Sympson's paradox ratio & 1 \\
\hline R-squared contribution ratio & 1 \\
\hline Statistical suppression ratio & 1 \\
\hline Nonlinear bivariate causality direction ratio & 1 \\
\hline Standardized root mean squared residual (SRMR) & 0.05 \\
\hline Standardized mean absolute residual (SMAR) & 0.04 \\
\hline Standardized chi-squared with 170 degrees of freedom & $1.54 * * *$ \\
\hline
\end{tabular}

Table 2. Properties of the goodness of measuring variables in the tested structural model

\begin{tabular}{|l|l|l|l|l|l|l|}
\hline & $\mathbf{R}^{2}$ & $\boldsymbol{\Delta} \mathbf{R}^{2}$ & $\mathbf{C R}$ & $\boldsymbol{\alpha}$ & $\mathbf{A V E}$ & VIFS \\
\hline EU & - & - & 0.97 & 0.96 & 0.87 & 1.45 \\
\hline PE & - & - & 0.98 & 0.98 & 0.93 & 1.12 \\
\hline PC & - & - & 0.98 & 0.98 & 0.94 & 1.28 \\
\hline PR & - & - & 0.96 & 0.94 & 0.90 & 1.08 \\
\hline HM & - & - & 0.97 & 0.97 & 0.92 & 1.29 \\
\hline Intention & 0.35 & 0.34 & 1.00 & 1.00 & 1.00 & 1.54 \\
\hline
\end{tabular}

Table 3. Results of the path model

\begin{tabular}{|l|l|l|l|}
\hline & $\boldsymbol{\beta}$ & $\mathbf{p}$ & $\mathbf{S E}$ \\
\hline EU ®Intention & 0.29 & $<0.001$ & 0.051 \\
\hline PE ®Intention & 0.19 & $<0.001$ & 0.052 \\
\hline PC ®Intention & 0.33 & $<0.001$ & 0.051 \\
\hline PR ®Intention & 0.04 & 0.218 & 0.053 \\
\hline HM ®Intention & 0.08 & 0.073 & 0.053 \\
\hline
\end{tabular}




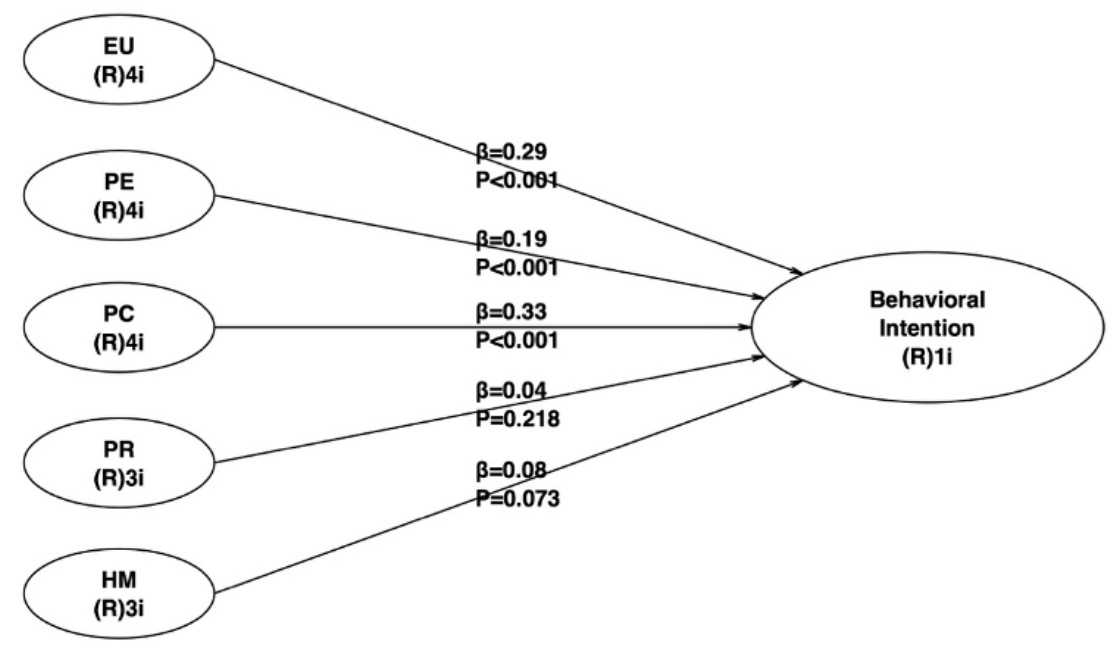

The perceived ease of deployment and use, PE, positively affects the intention of deploying and using an m-payment system by e-merchants. The research results confirmed that the perceived understanding, clarity, and ease of integration significantly and positively impact e-merchant's behavioral intention to accept an m-payment technology.

The perceived low cost, PC, have a positive impact on the intention of using the m-payment system. The study showed that in the whole model, the influence of PC is the strongest stimulus affecting e-merchant's intention to accept an m-payment system. The sale turnover of e-merchants significantly modifies the positive impact of Perceived cost, PC, on the intention of using the m-payment system. Turnover added a charge reinforcing PC's positive influence on intention. As the turnover increases, the strength of the relationship increases, and therefore, the path is strengthened. Declared experience in IT weakened the relationship between PC and intention.

Perceived risk, PR, appeared to be insignificant in these results. This is the most surprising result of the entire study. The significant effect of this exogenous variable on the behavioral intention of the tested e-merchants was not confirmed. This result contrasts with the intention of consumers. In numerous works, one can notice a significant impact of perceived risk on the intention and decisions of consumers.

The impact of PR itself is the lowest as compared to the other constructs. However, it should be noted that the p-factor is quite high compared to other variables, which means that the risk of the randomness of the obtained result is higher than in the case of other latent variables. Nevertheless, one may conclude that e-merchants do not consider threats related to m-payment systems and cooperation with the m-payment provider high.

The influence of PR on intention is unexpectedly low. Even when expressing security concerns, other factors appear to be stronger, and e-merchants' acceptance intention are not significantly impeded by the security risk. 
Table 4. Summary results of hypotheses verification or falsification

\begin{tabular}{|c|c|c|c|c|}
\hline Construct & $\begin{array}{l}\text { Hypothesis } \\
\text { Number }\end{array}$ & Moderator & Result & Comment \\
\hline \multirow{6}{*}{$\begin{array}{l}\text { Expected usefulness } \\
\text { (EU) }\end{array}$} & $\mathrm{H} 1$ & None & Supported & Direct effect \\
\hline & H1.1 & Age & Not Supported & Insignificant \\
\hline & $\mathrm{H} 1.2$ & Gender & Supported & Effect weaker for women \\
\hline & $\mathrm{H} 1.3$ & Turnover & Not Supported & Insignificant \\
\hline & H1.4 & Margin & Not Supported & Insignificant \\
\hline & H1.5 & Experience & Not Supported & Insignificant \\
\hline \multirow{6}{*}{$\begin{array}{l}\text { Perceived ease of } \\
\text { deployment and use (PE) }\end{array}$} & $\mathrm{H} 2$ & None & Supported & Direct effect \\
\hline & $\mathrm{H} 2.1$ & Age & Not Supported & Insignificant \\
\hline & $\mathrm{H} 2.2$ & Gender & Not Supported & Insignificant \\
\hline & $\mathrm{H} 2.3$ & Turnover & Supported & Effect stronger with increasing turnover \\
\hline & $\mathrm{H} 2.4$ & Margin & Supported & Effect weaker with increasing margin \\
\hline & $\mathrm{H} 2.5$ & Experience & Not Supported & Insignificant \\
\hline \multirow{6}{*}{ Perceived cost (PC) } & $\mathrm{H} 3$ & None & Supported & Direct effect \\
\hline & H3.1 & Age & Not Supported & Insignificant \\
\hline & $\mathrm{H} 3.2$ & Gender & Not Supported & Insignificant \\
\hline & $\mathrm{H} 3.3$ & Turnover & Supported & Effect stronger with increasing turnover \\
\hline & $\mathrm{H} 3.4$ & Margin & Not Supported & Insignificant \\
\hline & H3.5 & Experience & Supported & Effect weaker with increasing experience \\
\hline \multirow{6}{*}{ Perceived risk (PR) } & $\mathrm{H} 4$ & None & Not Supported & Insignificant \\
\hline & H4.1 & Age & Not Supported & Insignificant \\
\hline & $\mathrm{H} 4.2$ & Gender & Not Supported & Insignificant \\
\hline & $\mathrm{H} 4.3$ & Turnover & Not Supported & Insignificant \\
\hline & $\mathrm{H} 4.4$ & Margin & Not Supported & Insignificant \\
\hline & $\mathrm{H} 4.5$ & Experience & Not Supported & Insignificant \\
\hline \multirow{6}{*}{$\begin{array}{l}\text { Hedonistic motivation } \\
\text { (HM) }\end{array}$} & H5 & None & Supported & Direct effect \\
\hline & H5.1 & Age & Not Supported & Insignificant \\
\hline & $\mathrm{H} 5.2$ & Gender & Not Supported & Insignificant \\
\hline & H5.3 & Turnover & Not Supported & Insignificant \\
\hline & $\mathrm{H} 5.4$ & Margin & Supported & Effect weaker with increasing margin \\
\hline & H5.5 & Experience & Supported & Effect weaker with increasing experience \\
\hline
\end{tabular}

The hedonistic motivation was confirmed showing a relationship. The hedonic motivations positively influence the intention of using an m-payment system by e-merchants. Joy, pleasure, and entertainment related to the perception of m-payment system implementation had a slight impact on the acceptance of mobile technology and intention to use it.

Age did not moderate any relationship between constructs and merchants' behavioral intention $(\mathrm{p}>0.1)$. 
Gender significantly affected the relationship between PU and merchants' behavioral intention: $\beta=-0.11 ; t=2.05, p<0.1$. In the group of women, this relationship was significantly weaker than in the group of men. Gender did not moderate other constructs $(\mathrm{p}>0.05)$.

Turnover of sales significantly moderated the strength of the relationship between PE and merchants' behavioral intention $\beta=0.19, \mathrm{t}=3.58, \mathrm{p}<0.001$, as well as $\mathrm{PC}$ and merchants' behavioral intention $\beta=0.09, \mathrm{t}=1.75, \mathrm{p}<0.1$. With the increase of turnover, the strength of relationships between PU and merchants' behavioral intention, as well as PC and merchants' behavioral intention, increased significantly.

Margin significantly moderated the strength of the relationship between PE and merchants' behavioral intention $\beta=-0.19, \mathrm{t}=3.70, \mathrm{p}<0.1$, as well as $\mathrm{HM}$ and merchants' behavioral intention $\beta=-0.11, t=2.02, p<0.1$. With the increase of margin, the strength of the relationships decreased.

Experience in IT significantly moderated the relationship between PC and merchants' behavioral intention $\beta=-0.08, \mathrm{t}=1.49, \mathrm{p}<0.069$ and $\mathrm{HM} \beta=-0.10, \mathrm{t}=1.90, \mathrm{p}<0.1$. Experience in IT significantly weakened the relationship between PC and merchants' behavioral intention, as well as HM and merchants' behavioral intention.

The detailed results of the analysis of moderation are presented in Table 5. The most interesting results are italicized.

\section{DISCUSSION}

The MTAUT model presented in this paper permits us to predict an e-merchant's behavioral intention of launching an m-payment system. Based on advanced statistical methods, model MTAUT enabled the discovery of relationships between the determinants identified in the qualitative study and the intention of e-merchants. The research results presented in this paper concern on-line mobile purchases and payments only, so they are not distorted by purchases made in physical Points-Of-Sale using an m-payment technology, e.g., NFC technology. To our best knowledge, similar research results have not been published, so we cannot compare our results with others.

As follows from the quantitative research, the main determinants of the acceptance of m-payment systems by e-merchants are expected usefulness, and perceived cost and price. Expected usefulness has, however, weaker impact in cases where an e-merchant is female.

Turnover and margin appeared to have the greatest moderating influence on perceived ease of deployment and use. With increasing turnover, the construct "Perceived ease of deployment and use becomes more important, while with the increasing margin, it loses its importance. We conclude that for e-merchants generating high turnover, the perceived ease of deployment and use of an m-payment system is more important than other constructs. On the other hand, for e-merchants generating high margin, perceived ease of deployment and use of an m-payment system is not so important when compared to other constructs.

A similar phenomenon occurs in case of the relationship between e-merchant margins and impact of the hedonistic motivation on intention to accept an m-payment system. Increasing margins weaken this relationship. For e-merchants with higher margins, hedonistic motivation is less important when declaring intention.

Interestingly, the increasing turnover also modifies the strongest relationship in the entire study between the perceived cost of deployment of an m-payment system and the intention to use it. Along with the increase in turnover, the importance of perceived cost of deployment increases too, though to a relatively small extent. We suppose that such e-merchants expect that their relatively high turnover will affect the valuation of the m-payment system deployment.

Further, we observe that e-merchants with more IT experience tend to favor installing m-payment systems with fewer challenges to the system's cost. In other words, we conclude that e- merchants who are experienced in IT seem to have more understanding and acceptance of the factors underlying the 
Table 5. Moderation influence on the strength of compounds in the tested structural model

\begin{tabular}{|c|c|c|c|c|c|}
\hline Moderator & Influence & $\boldsymbol{\beta}$ & SE & $\mathbf{p}$ & $\mathbf{t}$ \\
\hline \multirow{5}{*}{ Age } & EU ®Intention & -0.01 & 0.05 & 0.422 & 0.20 \\
\hline & PE $® I n t e n t i o n$ & -0.04 & 0.05 & 0.220 & 0.77 \\
\hline & PC $® I n t e n t i o n$ & 0.07 & 0.05 & 0.106 & 1.25 \\
\hline & PR $® I n t e n t i o n$ & 0.04 & 0.05 & 0.253 & 0.67 \\
\hline & HM $®$ Intention & -0.03 & 0.05 & 0.308 & 0.50 \\
\hline \multirow{5}{*}{ Gender $($ women $=1 /$ men $=0)$} & EU ®Intention & -0.11 & 0.05 & 0.021 & 2.05 \\
\hline & PE $®$ Intention & 0.04 & 0.05 & 0.246 & 0.69 \\
\hline & PC $®$ Intention & -0.06 & 0.05 & 0.152 & 1.03 \\
\hline & PR @Intention & 0.05 & 0.05 & 0.192 & 0.87 \\
\hline & HM $®$ Intention & 0.03 & 0.05 & 0.307 & 0.51 \\
\hline \multirow{5}{*}{ Turnover } & EU $® I n t e n t i o n$ & 0.06 & 0.05 & 0.146 & 1.06 \\
\hline & PE $® I n t e n t i o n$ & 0.19 & 0.05 & $<0.001$ & 3.58 \\
\hline & PC $®$ Intention & 0.09 & 0.05 & 0.041 & 1.75 \\
\hline & PR $® I n t e n t i o n$ & -0.06 & 0.05 & 0.121 & 1.17 \\
\hline & HM ®Intention & 0.05 & 0.05 & 0.186 & 0.89 \\
\hline \multirow{5}{*}{ Margin } & EU $® I n t e n t i o n$ & 0.02 & 0.05 & 0.324 & 0.46 \\
\hline & PE ®Intention & -0.19 & 0.05 & $<0.001$ & 3.70 \\
\hline & PC $® I n t e n t i o n$ & -0.03 & 0.05 & 0.287 & 0.56 \\
\hline & PR $® I n t e n t i o n$ & -0.03 & 0.05 & 0.301 & 0.52 \\
\hline & HM $®$ Intention & -0.11 & 0.05 & 0.022 & 2.02 \\
\hline \multirow{5}{*}{ Experience in IT $(1=\mathrm{yes} / 0=\mathrm{no})$} & EU ®Intention & 0.06 & 0.05 & 0.142 & 1.08 \\
\hline & PE ®Intention & -0.07 & 0.05 & 0.107 & 1.25 \\
\hline & PC $®$ Intention & -0.08 & 0.05 & 0.069 & 1.49 \\
\hline & PR @Intention & 0.01 & 0.05 & 0.451 & 0.12 \\
\hline & HM ®Intention & -0.10 & 0.05 & 0.029 & 1.90 \\
\hline
\end{tabular}

cost of m-payment system acquisition and deployment. Similarly, with the increase of e-merchants' IT experience, the impact of hedonistic motivations weakens.

Unexpectedly, perceived risk was not a significant factor influencing e-merchants' intention to adopt an m-payment system. We suppose that this is a consequence of trust in the strict regulations affecting payment systems. If the institutions supervising and controlling payment operators allow a particular operator to function, then e-merchants conclude that the risk of cooperation with it is small. The study shows that the perceived risk is not only statistically insignificant, but also that its impact on the e-merchants' intention is the smallest of all the constructs.

The research results presented in this paper provide developers and marketers of m-payment systems with knowledge about factors that should be used as arguments to convince e-merchants to deploy m-payment systems. They should emphasize the expected usability, faster achievement of business goals and increased e-merchant's business performance following from the deployment and use of an m-payment system. It is also important to mention the importance of the cost-effectiveness of integrating an m-payment system with the technology platform currently used by an e-merchant, 
i.e., the ratio of the cost of deploying the m-payment system to its expected economic effects. On the other hand, factors related to risk and trust to the provider of the m-payment system need not be emphasized.

The academic value of the research presented lies in its contributions as a study of the factors affecting the acceptance of m-payment systems by e-merchants. It provides knowledge about an important missing element in understanding the entire m-commerce ecosystem. Model MTAUT devoted to intention of e-merchants complements model UTAUT devoted to intention of e-consumers. Model MTAUT may be used for further research. First, to investigate intention to use other systems than m-payment, and second, to investigate intention of other service providers than e-merchants.

\section{LIMITATIONS AND FUTURE RESEARCH GUIDELINES}

In the future, it would be very interesting to check how many e-merchants who were included in this study and expressed the intention of deployment of an m-payment system really bought a license and deployed one. It would be interesting to learn which constructs and moderators influenced their purchase decisions. The intention would then be a mediator for real commitments and signed contracts between an e-merchant and the contractor of m-payment system. It would also be interesting to learn how the behavioral intention mediated in the purchase decision and how the relationship between variables changed as a result of this mediation.

Further research should also be focused on the adaptation of the MTAUT model to other mobile systems used by e-merchants, such as financial and accounting systems, warehouse management systems, e-commerce platforms, advertising and sales analytics systems, and similar.

Moreover, it is worth investigating how cultural differences in different countries might modify the behavior of local e-merchants.

The study and the model presented in this paper are limited to e-merchants. In the future, it would be interesting to extend research on merchants who sell at physical points of sales. It will be interesting to compare behavioral intentions of both kinds of merchants with regard to acceptance of m-payment systems.

\section{ACKNOWLEDGMENT}

Many thanks to Louis E. Freund, Ph.D., Professor Emeritus in the Department of Industrial \& Systems Engineering at San Jose State University, San Jose, CA, USA, and to Dr. Marcin Szymkowiak from the Department of Statistics of the Poznan University of Economics and Business. The authors are grateful for their participation in many thorough discussions and for their comments that greatly improved the manuscript.

This research received no specific grant from any funding agency in the public, commercial, or not-for-profit sectors. 


\section{REFERENCES}

Ajzen, I. (1985). From intentions to actions: a theory of planned behavior. In Action Control. Springer.

Armitage, C. J., \& Conner, M. (2001). Efficacy of the theory of planned behaviour: A meta-analytic review. British Journal of Social Psychology, 10(4), 471-499.

Au, Y. A., \& Kauffman, R. J. (2008). The economics of mobile payments: Understanding stakeholder issues for an emerging financial technology application. Electronic Commerce Research and Applications, 7(2), 141-164.

Bose, A., \& Mellado, B. (2008). World payment report 2018. Capgemini, BNP PARISBAS. https:// worldpaymentsreport.com/resources/world-payments-report-2018/

Bright, I., \& McKenzie-Minifie, M. (2015). ING international surveys. ING eZonomics. https://www.ezonomics. com/ing_international_surveys/mobile_banking_2015/

Charland, A., \& Leroux, B. (2011). Mobile application development: Web vs. native. Communications of the ACM, 54(5), 49-53.

Dahlberg, T., Guo, J., \& Ondrus, J. (2015). A critical review of mobile payment research. Electronic Commerce Research and Applications, 14(5), 265-284.

de Graaf, M. M. A., Allouch, S. B., \& Van Dijk, J. A. G. M. (2017). Why do they refuse to use my robot? Reasons for non-use derived from a long-term home study. Proceedings of the ACM/IEEE International Conference on Human-Robot Interaction, 224-233.

Fishbein, M., \& Ajzen, I. (1975). Belief, attitude, intention, and behavior: An introduction to theory and research. Addison-Wesley.

Goodhue, D., Lewis, W., \& Thompson, R. (2006). PLS, Small sample size, and statistical power in MIS research. Proceedings of the 39th Annual Hawaii International Conference on System Sciences.

Guo, J., \& Bouwman, H. (2016). An analytical framework for an m-payment ecosystem: A merchants' perspective. Telecommunications Policy, 40(2), 147-167.

Hair, J. F., Hult, G. T. M., Ringle, C. M., \& Sarstedt, M. (2017). A primer on partial least squares structural equation modeling (PLS-SEM). Sage Publishing.

Hair, J. F., Ringle, C. M., \& Sarstedt, M. (2011). PLS-SEM: Indeed a silver bullet. Journal of Marketing Theory and Practice, 19(2), 139-152.

Hussain, A., \& Mkpojiogu, E. O. C. (2015). The effect of responsive web design on the user experience with laptop and smartphone devices. Journal Teknologi, 77(4), 41-47.

Iacobucci, D. (2010). Structural equations modeling: Fit indices, sample size, and advanced topics. Journal of Consumer Psychology, 20(1), 90-98.

Jones, M. (2018). Pen-And-Paper personal interviews (PAPI). The World Bank. Available: https://dimewiki. worldbank.org/wiki/Pen-and-Paper_Personal_Interviews_(PAPI)

5. Keys to Help Avoid Cart Abandonment. (2016). Baymard Institute, E-Commerce Usability: Checkout. https://www.visa.co.uk/dam/VCOM/regional/ve/unitedkingdom/PDF/vco-5keys-infographic.pdf

Klotzbach, C. (2018). Flurry state of mobile 2017: With captive mobile audiences, new app growth stagnates. Flurry. https://flurrymobile.tumblr.com/post/169545749110/state-of-mobile-2017-mobile-stagnates.

Kock, N. (2010). Using WarpPLS in e-collaboration studies: An overview of five main analysis steps. International Journal of e-Collaboration, 6(4), 1-11.

Kock, N. (2017). WarpPLS User Manual: Version 6.0. ScriptWarp Systems.

Kock, N., \& Gaskins, L. (2016). Simpson's paradox, moderation, and the emergence of quadratic relationships in path models: An information systems illustration. International Journal of Applied Nonlinear Science, 2(3), 200-234. 
Kock, N., \& Lynn, G. S. (2012). Lateral collinearity and misleading results in variance-based SEM: An illustration and recommendations. Journal of the Association for Information Systems, 13(7), 546-580.

Kock, N., \& Mayfield, M. (2015). PLS-based SEM algorithms: The good neighbor assumption, collinearity, and nonlinearity. Information Management Business Review, 7(2), 113-130.

Koufaris, M. (2002). Applying the technology acceptance model and flow theory to online consumer behavior. Information Systems Research, 13(2), 205-223.

Kousaridas, B., Parissis, G., \& Apostolopoulos, T. (2008). An open financial services architecture based on the use of intelligent mobile devices. Electronic Commerce Research and Applications, 7(2), 232-246.

Lai, D. C. F., Lai, I. K. W., \& Jordan, E. (2009). An extended UTAUT model for the study of negative user adoption behaviours of mobile commerce. International Conference on Electronic Business ICEB.

Lai, P. C. (2017). The literature review of technology adoption models and theories for the novelty technology. Journal of Information Systems and Technology Management, 14(1), 21-38.

Lai, P. M., \& Chuah, K. B. (2010). Developing an analytical framework for mobile payments adoption in retailing: A supply-side perspective. International Conference on Management of e-Commerce and e-Government, ICMeCG.

Liébana-Cabanillas, F., Muñoz-Leiva, F., \& Sánchez-Fernández, J. (2017). Examining merchants' refusal to adopt mobile payment systems in Spain. In N. Mohamudally (Ed.), Smartphones from an Applied Research Perspective (pp. 113-135). IntechOpen.

Liébana-Cabanillas, F., Slade, E., \& Dwivedi, Y. (2016). Time for a different perspective: A preliminary investigation of barriers to merchants' adoption of mobile payments. Proceedings of the 22nd Americas Conference on Information Systems, AMCIS 2016.

Ligon, E., Malick, B., Sheth, K., \& Trachtman, C. (2019). What explains low adoption of digital payment technologies? Evidence from small-scale merchants in Jaipur, India. PLoS One, 14(7). https://www.ncbi.nlm. nih.gov/pmc/articles/PMC6668901/

Mallat, N., \& Tuunainen, V. K. (2008). Exploring merchant adoption of mobile payment systems: An empirical study. e-Service Journal, 6(2), 24-57.

Meeker, M. (2018). Internet trends 2018. Kleiner Perkins. https://www.kleinerperkins.com/perspectives/internettrends-report-2018/

Mondego, D., \& Gide, E. (2018). The effect of trust on mobile payment adoption: A comprehensive review of literature. The International Journal of the Arts in Society, 11(01), 375-390.

Możdżyński, D. (2017). The conceptions of new payment methods based on revised payment services directive (PSD2). Information Systems Management, 6(1), 50-60.

Możdżyński, D. (2018). Acceptance of payment systems from the perspective of merchants. Information Systems Management, 7(1), 26-34.

Paper And Pencil Interviewing. (n.d.). Ninamedia Research. https://www.ninamedia.rs/en/research/services/ quantitative-methods/paper-and-pencil-interviewing/

Pearl, J. (2009). Causality: Models, reasoning and inference. Cambridge University Press.

Pearl, J. (2014). Understanding Simpson's paradox. The American Statistician, 68(1), 8-13.

Rogers, E. M. (1995). Diffusion of Innovations. Free Press.

Schweitzer, F., \& Van den Hende, E. A. (2016). To be or not to be in thrall to the march of smart products. Psychology and Marketing, 33(10), 830-842.

Silenzi, M. (2012). Mobile remote payment: An exploratory study of merchant adoption [Ph.D. dissertation]. Available: http://padis.uniroma1.it/handle/10805/1545

Tenenhaus, M., Esposito, V. E., Chatelin, Y. M., \& Lauro, C. (2005). PLS path modeling. Computational Statistics \& Data Analysis, 48(1), 159-205. 
Teo, E., Fraunholz, B., \& Unnithan, C. (2005). Inhibitors and facilitators for mobile payment adoption in Australia: A preliminary study. Proceedings of the International Conference on Mobile Business, 663-666.

The Mobile Money Revolution Part 1: NFC Mobile Payments, ITU-T Technology Watch Report. (2013). International Telecommunications Union. https://www.itu.int/dms_pub/itu-t/oth/23/01/T23010000200001PDFE. pdf

Van Der Heijden, H. (2002). Factors affecting the successful introduction of mobile payment systems. Proceedings of the 15th Bled eConference: eReality: Constructing the eEconomy, 20.

Venkatesh, V., Morris, M. G., Davis, G. B., \& Davis, F. D. (2003). User acceptance of information technology: Toward a unified view. Management Information Systems Quarterly, 27(3), 425-478.

Venkatesh, V., Thong, J. Y. L., \& Xu, X. (2012). Consumer acceptance and use of information technology: Extending the unified theory of acceptance and use of technology. Management Information Systems Quarterly, $36(1), 157-178$.

Webster, J., \& Watson, R. T. (2002). Analyzing the past to prepare for the future: Writing a literature review. Management Information Systems Quarterly, 26(2), 13-23.

Welch, K. (2017). How To Optimize Your Mobile E-Commerce Checkout Page. Forbes. Available: https:// www.forbes.com/sites/forbescommunicationscouncil/2017/06/01/how-to-optimize-your-mobile-e-commercecheckout-page/\#7dfc31b5cd2d

Wu, J. H., \& Wang, S. C. (2005). What drives mobile commerce An empirical evaluation of the revised technology acceptance model. Information \& Management, (42), 719-729.

Yang, Q., Pang, C., Liu, L., Yen, D. C., \& Tarn, M. (2015). Exploring consumer perceived risk and trust for online payments: An empirical study in China's younger generation. Computers in Human Behavior, 50, 9-24. 


\section{APPENDIX A - LIST OF CATEGORIES WITH NUMBER OF MENTIONS}

\begin{tabular}{|c|c|c|c|}
\hline Category & Definition & Example of mention & $\begin{array}{l}\text { Number of } \\
\text { mentions }\end{array}$ \\
\hline Expected usefulness & $\begin{array}{l}\text { Conviction that the use of an } \\
\text { m-payment system will provide an } \\
\text { e-merchant with benefits }\end{array}$ & $\begin{array}{l}\text { "Deployment of an } \\
\text { m-payment system will } \\
\text { increase the efficiency } \\
\text { of my business" }\end{array}$ & 38 \\
\hline $\begin{array}{l}\text { Perceived ease of deployment } \\
\text { and use }\end{array}$ & $\begin{array}{l}\text { How easy an e-merchant assumes it } \\
\text { will be to deploy, maintain, and use an } \\
\text { m-payment system }\end{array}$ & $\begin{array}{l}\text { "I consider an } \\
\text { m-payment system easy } \\
\text { to use" }\end{array}$ & 23 \\
\hline Perceived cost & $\begin{array}{l}\text { Expected costs to be covered if an } \\
\text { e-merchant purchases an m-payment } \\
\text { system for his/her business }\end{array}$ & $\begin{array}{l}\text { "Commissions are } \\
\text { reasonable" }\end{array}$ & 42 \\
\hline Perceived risk & $\begin{array}{l}\text { Perception of the risk of cooperation } \\
\text { with an m-payment system provider } \\
\text { and trust based on provider reputation } \\
\text { concerning transaction security. }\end{array}$ & $\begin{array}{l}\text { "I consider mobile } \\
\text { payments as unsafe" }\end{array}$ & 17 \\
\hline Hedonistic motivation & $\begin{array}{l}\text { Joy and pleasure an e-merchant } \\
\text { expects from using an m-payment } \\
\text { system. }\end{array}$ & $\begin{array}{l}\text { "It is nice to have an } \\
\text { m-payment system and } \\
\text { it's important to me do } \\
\text { deploy system that fits } \\
\text { (visually, in terms of } \\
\text { color, logo, name, etc.) } \\
\text { with my e-shop" }\end{array}$ & 6 \\
\hline Age & Age of an e-merchant & $\begin{array}{l}\text { "This type of } \\
\text { innovations is not for } \\
\text { people of my age" }\end{array}$ & 9 \\
\hline Gender & Gender of an e-merchant & $\begin{array}{l}\text { "For me, as a woman, } \\
\text { the most important } \\
\text { thing is the aesthetics, } \\
\text { including colors } \\
\text { used and harmonious } \\
\text { matching of the } \\
\text { m-payment interface } \\
\text { to the interface of my } \\
\text { e-shop" }\end{array}$ & 7 \\
\hline Turnover & Turnover of an e-merchant's company & $\begin{array}{l}\text { "Such system may be } \\
\text { of interest to companies } \\
\text { with more turnover than } \\
\text { mine" }\end{array}$ & 14 \\
\hline Margin & $\begin{array}{l}\text { Margin of profit of an e-merchant } \\
\text { company }\end{array}$ & $\begin{array}{l}\text { "Maybe we would } \\
\text { deploy and m-payment } \\
\text { system if we operated on } \\
\text { higher margins" }\end{array}$ & 18 \\
\hline Experience in IT & $\begin{array}{l}\text { Experience in IT systems declared } \\
\text { by an e-merchant or his/her deputy } \\
\text { making business decisions }\end{array}$ & $\begin{array}{l}\text { "I don't know IT enough } \\
\text { to discuss about such } \\
\text { topics" }\end{array}$ & 26 \\
\hline
\end{tabular}




\section{APPENDIX B - QUESTIONNAIRE OF THE MOBILE PAYMENT SYSTEM ACCEPTANCE}

Interview technique: Paper and Pen Personal Interview PAPI

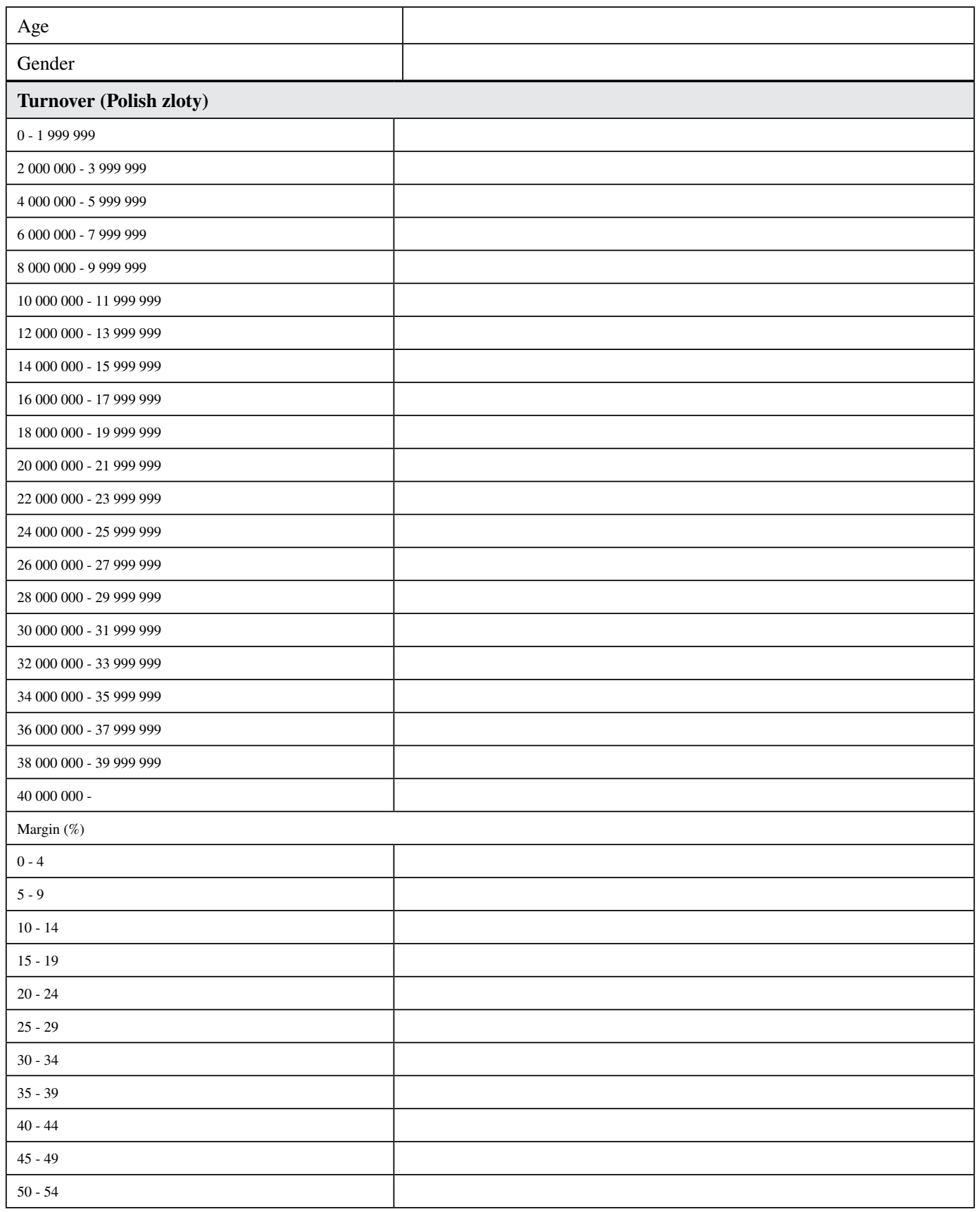




\section{Table Continued}

\begin{tabular}{|c|c|c|c|c|c|c|c|c|c|}
\hline \multicolumn{10}{|c|}{ Turnover (Polish zloty) } \\
\hline \multicolumn{10}{|l|}{$55-59$} \\
\hline \multicolumn{10}{|l|}{$60-64$} \\
\hline \multicolumn{10}{|l|}{$65-69$} \\
\hline \multicolumn{10}{|l|}{$70-74$} \\
\hline \multicolumn{10}{|l|}{$75-79$} \\
\hline \multicolumn{10}{|l|}{$80-84$} \\
\hline \multicolumn{10}{|l|}{$85-89$} \\
\hline \multicolumn{10}{|l|}{$90-94$} \\
\hline \multicolumn{10}{|l|}{$95-$} \\
\hline \multicolumn{10}{|l|}{ IT experience } \\
\hline \multirow{2}{*}{\multicolumn{3}{|c|}{ I have IT competence in the area of integrating an online shop with a payment system }} & \multicolumn{7}{|c|}{ Yes/No } \\
\hline & & & 1 & 2 & 3 & 4 & 5 & 6 & 7 \\
\hline \multirow{4}{*}{ Expected usefulness } & EUS1 & I consider an m-payment system useful in my business & & & & & & & \\
\hline & EUS2 & $\begin{array}{l}\text { Handling mobile payments will allow me to achieve } \\
\text { business goals that are important to me }\end{array}$ & & & & & & & \\
\hline & EUS3 & $\begin{array}{l}\text { An m-payment system will allow me to achieve my business } \\
\text { goals faster }\end{array}$ & & & & & & & \\
\hline & EUS4 & $\begin{array}{l}\text { Deployment of an m-payment system will increase the } \\
\text { efficiency of my business }\end{array}$ & & & & & & & \\
\hline \multirow{4}{*}{$\begin{array}{l}\text { Perceived ease of } \\
\text { deployment and use }\end{array}$} & PEU1 & $\begin{array}{l}\text { Deployment of an m-payment system seems easy in my } \\
\text { company }\end{array}$ & & & & & & & \\
\hline & PEU2 & For me, interaction with an m-payment system is clear & & & & & & & \\
\hline & PEU3 & I consider an m-payment system easy to use & & & & & & & \\
\hline & PEU4 & $\begin{array}{l}\text { It is easy for me to acquire skills necessary to use an } \\
\text { m-payment system }\end{array}$ & & & & & & & \\
\hline \multirow{4}{*}{ Perceived cost } & PCO1 & Commissions are reasonable & & & & & & & \\
\hline & $\mathrm{PCO} 2$ & Deployment cost represents good price/value ratio & & & & & & & \\
\hline & $\mathrm{PCO} 3$ & $\begin{array}{l}\text { At current cost of use, an m-payment system is profitable } \\
\text { and worth deployment }\end{array}$ & & & & & & & \\
\hline & $\mathrm{PCO} 4$ & Total cost of m-payment system use is beneficial & & & & & & & \\
\hline \multirow{3}{*}{ Perceived risk } & PRI1 & $\begin{array}{l}\text { I feel uncertainty and concerns about selling via the mobile } \\
\text { channel }\end{array}$ & & & & & & & \\
\hline & PRI2 & $\begin{array}{l}\text { I consider cooperation with an m-payment system provider } \\
\text { as risky }\end{array}$ & & & & & & & \\
\hline & PRI3 & I consider mobile payments as unsafe & & & & & & & \\
\hline \multirow{3}{*}{ Hedonic motivation } & PHM1 & $\begin{array}{l}\text { I believe that deployment of an m-payment system will } \\
\text { provide me with joy and satisfaction }\end{array}$ & & & & & & & \\
\hline & PHM2 & $\begin{array}{l}\text { I believe that deployment of an m-payment system will keep } \\
\text { me entertained }\end{array}$ & & & & & & & \\
\hline & PHM3 & $\begin{array}{l}\text { It is important to me do deploy an m-payment system that } \\
\text { fits (visually, in terms of color, name, etc.) with my e-shop }\end{array}$ & & & & & & & \\
\hline
\end{tabular}


Daniel Możdżyński received his Master's degree at the Faculty of Economics and Management - "IT and Econometrics" of the University of Szczecin in 1999. He is a graduate of WSB Universities MBA program in cooperation with Franklin University in Ohio. In 2016 he graduated from postgraduate studies at the WSB Universities - „IT Project Manager”. In 2014 he started his Ph.D. studies at the Faculty of Informatics and Electronic Economy at the Poznań University of Economics. He is present at the IT market for 15 years. He gained his experience in such companies as: HP, Fujitsu-Siemens, GE Security and in leading ICT solutions integrators.

Wojciech Cellary received the Ph.D. from the Poznan University of Technology (Poland). From 1974-92 he was with that university, from 1987-91 serving as the scientific director of the Institute of Computing Science. From 1992-96 he served as the vice-president responsible for research of the Franco-Polish School of New Information and Communication Technologies. In 1996 he joined the Poznan University of Economics. He has been a visiting professor at 4 universities in France, 2 in Italy, 1 in Macao and 1 in Portugal. He has been a leader of numerous research and industrial projects on the development of hardware and software of computer systems and their applications. He has been a main organizer of 59 scientific conferences a member of the program committees of an additional 350 conferences. He is an author or co-author of 10 books, 30 chapters in books, and over 150 articles in journals and conference proceedings. He is an editor of 17 books. He teaches courses on electronic business both in Polish and English attended by 500-1000 students annually. 